\title{
Ceftriaxone and clavulanic acid induce antiallodynia and anti-inflammatory effects in rats using the carrageenan model
}

This article was published in the following Dove Press journal:

Journal of Pain Research

\author{
Abraham Ochoa-Aguilar ${ }^{1,2}$ \\ Rosa Ventura-Martinez' \\ Marco Antonio \\ Sotomayor-Sobrino' \\ Ruth Jaimez' \\ Ulises Coffeen ${ }^{3}$ \\ Ariadna Jiménez-González ${ }^{2}$ \\ Luis Gerardo \\ Balcázar-Ochoa' \\ Rafael \\ Pérez-Medina-Carballo ${ }^{2}$ \\ Rodolfo Rodriguez' \\ Ricardo Plancarte-Sánchez ${ }^{4}$ \\ 'Pharmacology Department, Faculty \\ of Medicine, National Autonomous \\ University of Mexico, Mexico City, \\ México; ${ }^{2}$ Research Department, \\ Mexican Faculty of Medicine, La Salle \\ University, Mexico City, México; \\ ${ }^{3}$ Instituto Nacional de Psiquiatría \\ Ramón de la Fuente Muñiz, Mexico \\ City, México; ${ }^{4}$ Pain Clinic, National \\ Cancer Institute of Mexico, Mexico \\ City, México
}

Introduction: Ceftriaxone (CFX) and clavulanic acid (CA) are $2 \beta$-lactam molecules widely used as antibiotics. However, several reports of their antiallodynic properties have been published in recent years. Although this effect has been considered mostly due to a GLT1 overexpression, these molecules have also been proven to induce direct immunomodulation. In this work, we determine the acute analgesic effect of CFX and CA in an inflammatory pain model and assess if their administration may induce anti-inflammatory effects.

Methods: The carrageenan (Carr) test was used as an inflammatory pain model. Both mechanical and thermal responses were analyzed after CFX and CA administration at different times. A plethysmometer was used to determine inflammation. Also, TNF- $\alpha$ and IL-10 serum concentrations were determined by enzyme-linked immunosorbent assay.

Results: Both CFX and CA induced a significant thermal antiallodynic effect 3 and $24 \mathrm{~h}$ after administration. Furthermore, CA induced a mechanical antiallodynic effect 30, 60, and 90 min after administration. Moreover, a significant anti-inflammatory effect was found for both molecules $24 \mathrm{~h}$ after Carr injection. Also, both CA and CFX modulated TNF- $\alpha$ and IL-10 serum concentrations at different times.

Conclusion: Our results provide evidence that both CFX and CA cause an analgesic effect on a Carr inflammatory pain model and that said analgesic effect differs between each $\beta$-lactam molecule. Furthermore, this effect may be related to an anti-inflammatory effect of both molecules and a direct TNF- $\alpha$ and IL-10 serum concentration modulation.

Keywords: ceftriaxone, clavulanic acid, inflammatory pain, TNF- $\alpha$ concentration, $\beta$-lactam molecules, analgesic effect, antiallodynic properties

\section{Introduction}

Ceftriaxone (CFX) and clavulanic acid (CA) are part of a group of drugs known as $\beta$-lactam molecules (BLMs), so named due to the presence of an azetidinone nucleus containing a cyclic amide with the carbonyl $\beta$-lactams, also known as $\beta$-lactam ring. ${ }^{1}$ CFX and CA are both currently clinically being used as antibiotics; however, CA's mechanism of action has only been considered as an antibiotic adjuvant (since it inhibits penicillinase proteins on the bacterial cell wall $)^{2}$ and is known to have a negligible antibiotic effect by itself. ${ }^{3}$ Both BLMs have recently been shown to induce analgesia in murine ${ }^{2,4}$ and/or human ${ }^{5}$ protocols.

This analgesic effect has been mainly attributed to a glutamatergic modulation induced by administering any BLM as this has been largely shown to upregulate the expression of GLT1 in human astrocytes. ${ }^{6,7}$ This upregulation has been previously
Correspondence: Abraham

Ochoa-Aguilar

Facultad Mexicana de Medicina

Universidad La Salle, Fuentes \#I7,

Tlalpan, 14000, Mexico City, México

Tel +52 5525593012

Email dr.abraham.ochoa@gmail.com 
proven to be apparent no less than 7 hours after CFX administration $^{5}$ in rats. However, our group has previously found an acute antiallodynic effect in a neuropathic pain model only 30 min after CA or CFX administration and that this effect was related to a reduction in TNF- $\alpha$ serum concentration. ${ }^{8}$

On the other hand, inflammatory pain pathophysiology is a complex mechanism, which involves a change in the regulation of proinflammatory (such as TNF- $\alpha$ ) and antiinflammatory (IL-10) molecules. ${ }^{9}$ When this physiological mechanism is activated, it induces not only pain but also an increase in tissue volume known as edema.

Regarding this type of pain, BLMs have also been shown to have an analgesic effect as CFX has been proven to have analgesic and antihyperalgesic effects when administered once daily for 7 days prior to carrageenan (Carr) intraplantar injection. ${ }^{4}$ Moreover, there have been some clinical reports of a successful treatment of long-standing regional pain syndrome by another BLM, cefadroxil. ${ }^{11}$ Furthermore, CA administration has been shown to induce an anti-inflammatory effect in high doses in a Carr-induced inflammation model, ${ }^{5}$ which would point toward a possible effect of this molecule in this type of pain.

BLMs have been used in the clinical field for a long time as antibiotics owing to their safety and tolerability. ${ }^{1} \mathrm{~A}$ new potential indication for commercial use of BLMs could lead to a very fast implementation in the health care setting with low costs; besides, their relatively simple chemical structure can lead to the development of new drugs for the relief of pain. However, it is important first to demonstrate their efficacy in several types of pain and try to understand mechanisms involved in this effect.

Given this evidence, the aim of this study was to determine the analgesic and anti-inflammatory effects of the administration of CFX and CA in a Carr-induced inflammatory pain model in an acute time frame. We also studied the possible effects on cytokine levels and assessed if this would have any effect on the edema exerted by Carr administration.

\section{Methods and materials}

The experiments were conducted in agreement with the ethics committee regulations of the International Association for the Study of Pain ${ }^{13}$ and the Mexican Official Norm for Animal Care and Handling. ${ }^{14}$ They also were approved by Institutional Ethics Commissions (Faculty of Medicine UNAM, No. 012-2015 and with the ethical committee approval of the Instituto Nacional de Psiquiatría Ramón de la Fuente Muñiz [CONBIOETICA-09-CEI-010-20170316]). The number of experimental animals was kept to a minimum ( $\mathrm{n}=8$ for every group), and rats were euthanized by $\mathrm{CO}_{2}$ overdoses or by exsanguination in the case of those from which a blood sample was taken for cytokine measurement (vide infra).

\section{Animals}

Male Wistar rats (200-250 g) were raised, housed, and maintained in the facilities of the institution. The animals were kept in transparent acrylic individual cages, with light/dark cycles of 12/12 h, and with ad libitum feeding and hydration. To reduce stress, the rats underwent 20 min habituation sessions for 5 consecutive days in the experimental acrylic cages. For all nociceptive procedures, the rats were anesthetized with isoflurane $2 \%$.

\section{Drugs}

Diclofenac (DIC, $10 \mathrm{mg} / \mathrm{kg}$ ) (Sigma, St. Louis, MO, USA), potassium clavulanate (CA, $10 \mathrm{mg} / \mathrm{kg}$ ) (Sigma), and ceftriaxone (CFX, $200 \mathrm{mg} / \mathrm{kg}$ ) (Pisa, Mexico City, Mexico) were dissolved in saline solution $(0.9 \% \mathrm{NaCl})$. All the compounds were prepared immediately before being intraperitoneally (IP) administered, at a final volume of $1 \mathrm{~mL} / \mathrm{kg}$ of body weight. Doses of all drugs were conclusively determined in previous studies. ${ }^{8}$

\section{Inflammatory procedure}

Prior to the inflammatory process, rats were kept inside an anesthetic chamber and slightly anesthetized ( $2 \%$ isoflurane). The inflammatory process was induced by the intraplantar injection of carrageenan lambda (Sigma Chemical Co.; 1\% Carr in saline solution, $250 \mu \mathrm{L}$ ) into the right hind paw. DIC was used as positive control due to its wide use in inflammatory pain.

The day of the behavioral evaluation, CFX $(200 \mathrm{mg} /$ $\mathrm{kg})$, CA $(10 \mathrm{mg} / \mathrm{kg})$, DIC $(10 \mathrm{mg} / \mathrm{kg})$, or saline solution (control group) were administered to animals IP. Following administration, pain-related behaviors were assessed every $30 \mathrm{~min}$ for $180 \mathrm{~min}$ for the mechanical allodynia model and at 3 and $24 \mathrm{~h}$ for thermal nociception model. The baseline assessment was made 30 min prior to either drug or saline administration. Finally, after the last behavioral evaluation, 4 rats of each group were randomly selected and a blood sample was obtained to assess the concentration of TNF- $\alpha$ and IL-10 (vide infra).

\section{Behavioral evaluation}

\section{Mechanical allodynia (Von Frey filament test)}

To assess mechanical allodynia, calibrated nylon monofilament fibers with an increasing range of bending force (Von Frey hairs; Stoelting, Wood Dale, IL, USA) were applied in 
increasing order (1-15 g of force) to the right hind footpad to elicit paw withdrawal responses using the Bennett's model. ${ }^{15}$ The cut-off point was established at $15 \mathrm{~g}$ to avoid tissue injury.

The rats were placed in acrylic cages on top of a wire mesh that allowed access to the filaments of the right hind footpad. Beginning with the lowest force, the filament was placed on the skin until it bowed slightly, with each filament presented 5 times at a rate of about $1 \mathrm{sec}$. A response was recognized if the rat withdrew its hind paw from the filament on 3 out of 5 occasions, and the amount of force was recorded. Data are presented as the mean \pm standard error of the mean (SEM) of the paw withdrawal threshold (PWT) per experimental group, expressed in grams (g).

\section{Thermonociception (Plantar test)}

The thermonociceptive response was elicited by applying punctual radiant heat in the Plantar Test Apparatus (Ugo Basile, mod7370, Gemonio VA, Italy) according to the Hargreaves Method. ${ }^{39}$ Paw withdrawal latency (PWL) was determined for the right paw to the nearest $0.1 \mathrm{sec}$ using the electronic timer in the device. Cut-off time was $20 \mathrm{sec}$ to avoid tissue injury. Each determination was made with the average of 3 trials per hind paw. All groups were tested prior to the induction of inflammation to determine the nociceptive threshold (acute pain). Also, the PWL was measured at different times following Carr intraplantar injection.

\section{Edema measurement}

To test the evolution of the inflammatory response induced by Carr injection (vide supra) and to screen potential antiinflammatory or antiedema properties of injected substances, we used a digital water plethysmometer (Ugo Basile 37140). The Plethysmometer Control Unit detects the water displacement produced by the immersion of the animal paw and generates an output signal to the digital display indicating the volume displacement measured $(0.01 \mathrm{~mL}$ resolution). The right hind paw of each animal was submerged to the level of the calcaneal tibial joint and the volume displacement was registered 3 times for each rat. The mean value for each rat was obtained, and data were expressed as total paw volume (TPV).

\section{Cytokine assessment}

The blood samples were taken under deep pentobarbital anesthesia (36 mg/kg, IP), from the abdominal aorta in a vacutainer. Whole blood samples were centrifuged at 3,000 rpm for $20 \mathrm{~min}$; serum was separated and stored at $-20^{\circ} \mathrm{C}$.
The levels of serum TNF- $\alpha$ and IL-10 were quantified using indirect enzyme-linked immunosorbent assay kits (TNF- $\alpha$ Abcam, ab46070 and IL-10 Abcam 100764; Cambridge, MA, USA), following manufacturer's instructions. The cytokine contents in the samples were expressed as picograms of antigen per milliliter of serum $(\mathrm{pg} / \mathrm{mL})$.

\section{Statistical analysis}

Statistical analysis was performed using GraphPad 6 PRISM software (GraphPad Software, San Diego, CA, USA). For statistical analysis of behavioral data, a 2-way analysis of variance (ANOVA) was performed, followed by a Dunnett post hoc test to determine the significant differences among the groups in each time point (time $0,30,60,90,120$, and $180 \mathrm{~min}$; and 3, 24, and $48 \mathrm{~h}$ ). In time curves of behavioral results and TPV data are presented as the mean \pm SEM. Also, 2-way ANOVA was used to assess the differences in cytokine concentrations, followed by Dunnett post hoc test. Data are presented as the mean \pm SEM. A $p$-value $<0.05$ was considered significant for all tests.

\section{Results Mechanical allodynia}

All sham animals exhibited a withdrawal response at the previously set cut-off point of $15 \mathrm{~g}$, similar to previous reports throughout the whole experiment. One hour after Carr administration, there was a significant decrease in PWT compared to SHAM group through the whole experiment $(3.71 \pm 0.68$ $\mathrm{g} ; p<0.05$ ). DIC administration (a positive control) induced a significant increase in PWT throughout the first $180 \mathrm{~min}$ (maximum effect $90 \mathrm{~min}$ after administration, $8.5 \pm 0.36 \mathrm{~g}$ ) as well as at $24(7.5 \pm 1.60 \mathrm{~g})$ and $48 \mathrm{~h}(9.4 \pm 1.60 \mathrm{~g})$ after Carr injection (Figure $1 \mathrm{~A}$ and $\mathrm{B}$ ).

CFX (200 mg/kg) administration did not induce any significant acute antiallodynic effect at any time $(30,60,90$, $120,150$, and $180 \mathrm{~min})$ of observation $(2.8 \pm 0.59,2.2 \pm 0.28$, $4.5 \pm 1.04,4.2 \pm 0.52,4.2 \pm 0.68$ and $3.1 \pm 0.59 \mathrm{~g}$, respectively; $p>0.05)$. However, continued administration of CFX did elicit such an effect at $24(11.2 \pm 1.40$ vs $6.8 \pm 0.73 \mathrm{~g}$ Carr; $p<0.05)$ and $48 \mathrm{~h}(11.4 \pm 0.92$ vs $6.5 \pm 0.57 \mathrm{~g}$ Carr; $p<0.05)$ after Carr injection (Figure 1C and D).

On the other hand, CA $(10 \mathrm{mg} / \mathrm{kg})$ did elicit significant antiallodynia at 30 ( $7.5 \pm 1.34$ vs $2.5 \pm 0.36 \mathrm{~g}$ Carr; $p<0.05), 60$

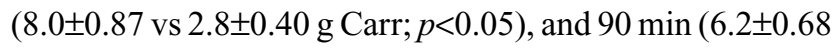
vs $2.5 \pm 0.36 \mathrm{~g}$ Carr; $p<0.05)$ after administration. Furthermore, this effect was also found at the $24(11.2 \pm 1.14 \mathrm{vs}$ $6.8 \pm 0.73 \mathrm{~g}$ Carr; $p<0.05)$ and $48 \mathrm{~h}(10.8 \pm 1.12$ vs $6.5 \pm 0.57 \mathrm{~g}$ Carr; $p<0.05$ ) observation times (Figure 1E and F). 

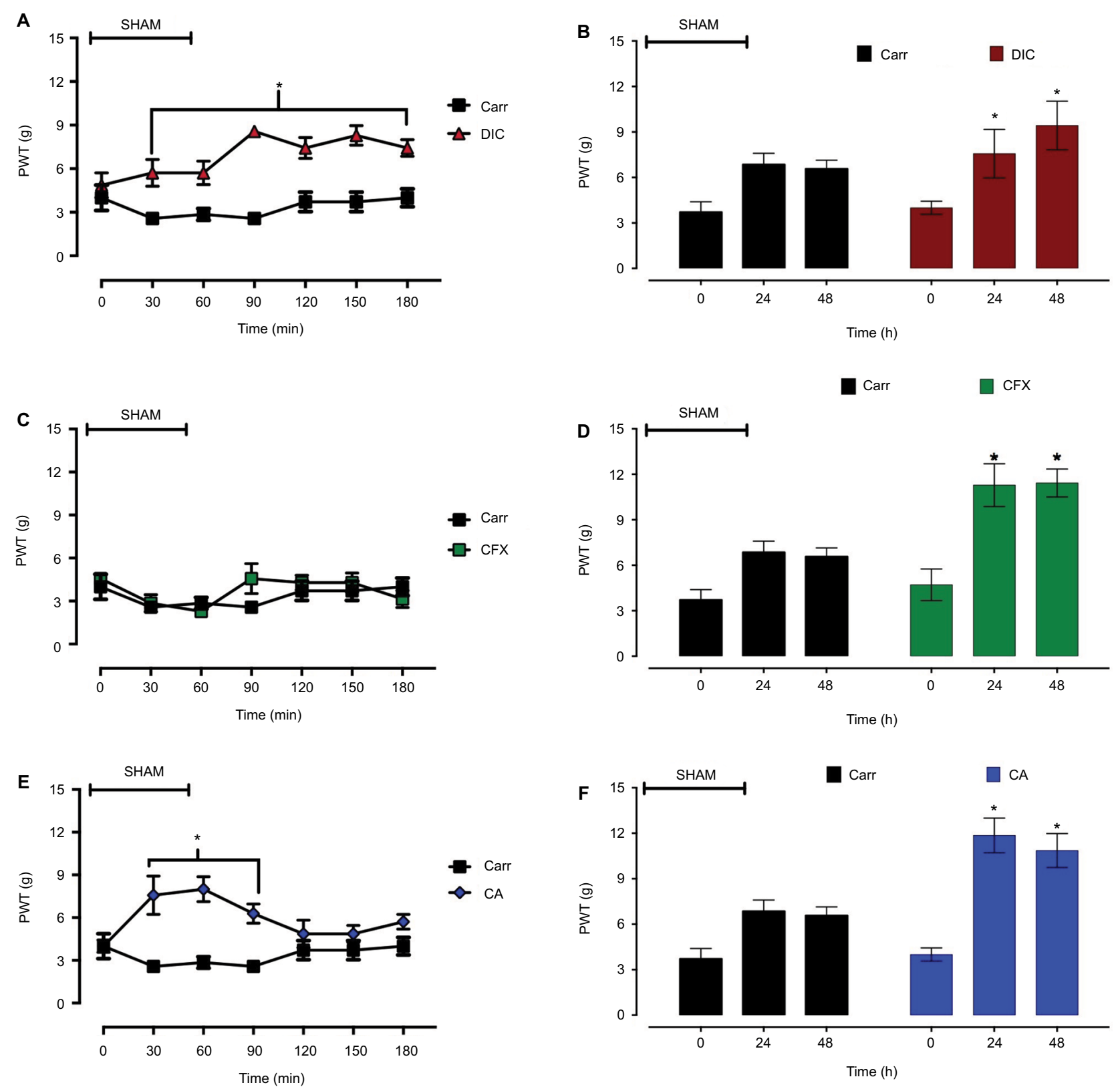

Figure I Mechanical allodynia induced by Carr and the analgesic effect of drug administration.

Notes: (A) Antiallodynic effect of DIC (10 mg/kg, IP) during $180 \mathrm{~min}$; (B) antiallodynic effect of DIC (10 mg/kg, IP) at 0, 24, and $48 \mathrm{~h}$; (C) antiallodynic effect of CFX (200 $\mathrm{mg} / \mathrm{kg}$, IP) during $180 \mathrm{~min} ;$ (D) antiallodynic effect of CFX (200 mg/kg, IP) at 3, 24, and $48 \mathrm{~h} ;$ (E) antiallodynic effect of CA (10 mg/kg, IP) during $180 \mathrm{~min} ;$ (F) antiallodynic effect of CA (10 mg/kg, IP) at 3, 24, and $48 \mathrm{~h}$. Values are the mean \pm SEM of 8 rats per group. ${ }^{*} p<0.05$ vs Carr group (2 way ANOVA followed by a Dunnett post hoc test). Abbreviations: ANOVA, analysis of variance; CA, clavulanic acid; Carr, carrageenan; CFX, ceftriaxone; DIC, diclofenac; IP, intraperitoneal; PWT, paw withdrawal threshold; SEM, standard error of the mean.

\section{Thermal allodynia}

As described in the "Methods and materials" section, we performed an initial observation prior to Carr administration. There was no significant difference between DIC, CFX, and CA with Carr $(7.6 \pm 0.18,7.7 \pm 0.28$, and $7.8 \pm 0.27$ vs $7.9 \pm 0.64$ sec, respectively) (Figure 2). After Carr administration, there was a significant difference in PWL in Carr group at the 3 $(4.4 \pm 0.29$ vs $7.9 \pm 0.64 \mathrm{sec} ; p<0.05)$ and $24 \mathrm{~h}(4.3 \pm 0.29$ vs
$7.9 \pm 0.64 \mathrm{sec} ; p<0.05)$ time points. On the other hand, DIC administration induced an increase in PWL at $3(6.2 \pm 0.58$ vs $4.4 \pm 0.29 \mathrm{sec} ; p<0.05)$ and $24 \mathrm{~h}(6.0 \pm 0.47$ vs $4.3 \pm 0.29$ sec; $p<0.05)$ in comparison with Carr at the corresponding time (Figure 2A). Meanwhile, CFX administration induced a significant increase in PWL at $3(6.5 \pm 0.29$ vs $4.4 \pm 0.29$ sec; $p<0.05)$ and $24 \mathrm{~h}(6.5 \pm 0.62$ vs $4.3 \pm 0.29 \mathrm{sec} ; p<0.05)$ in comparison with Carr at the corresponding time (Figure 2B). 
Furthermore, there was also a significant increase after CA administration in PWT at the $3(5.9 \pm 0.26$ vs $2.2 \pm 0.29 \mathrm{sec}$; $p<0.05)$ and $24 \mathrm{~h}(6.8 \pm 0.34$ vs $4.3 \pm 0.29 \mathrm{sec} ; p<0.05)$ in comparison with Carr at the corresponding time (Figure 2C).

\section{Paw edema}

SHAM group did not show any significant difference in TPV at any observation time $(0,3$, and $24 \mathrm{~h})(1.1 \pm 0.02,1.0 \pm 0.02$ and $1.1 \pm 0.01 \mathrm{~cm}^{3}$, respectively). After Carr administration there was a significant increase in TPV at $3(2.2 \pm 0.08$ vs $\left.1.0 \pm 0.02 \mathrm{~cm}^{3} ; p<0.05\right)$ and $24 \mathrm{~h}\left(2.0 \pm 0.09\right.$ vs $1.1 \pm 0.01 \mathrm{~cm}^{3}$; $p<0.05)$ after intraplantar Carr administration. On the other hand, DIC administration induced a significant decrease in TPV at $3\left(1.9 \pm 0.10\right.$ vs $\left.2.2 \pm 0.08 \mathrm{~cm}^{3} ; p<0.05\right)$ and $24 \mathrm{~h}$ $\left(1.3 \pm 0.03\right.$ vs $\left.2.0 \pm 0.09 \mathrm{~cm}^{3} ; p<0.05\right)$ in comparison with Carr at the corresponding time (Figure 3). Meanwhile, although CFX administration did not induce any effect in TPV at $3 \mathrm{~h}$ observation ( $2.4 \pm 0.08$ vs $2.2 \pm 0.08 \mathrm{~cm}^{3} ; p>0.05$ ), this group

Plantar test

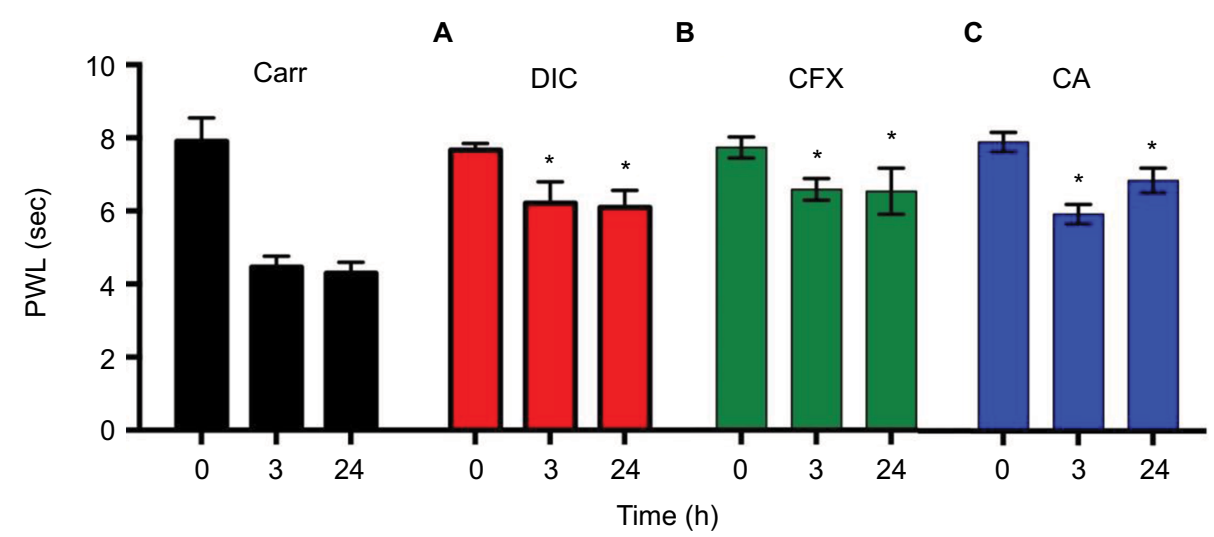

Figure 2 Thermal allodynia induced by Carr and the antiallodynic effect of drug administration.

Notes: (A) Antiallodynic effect of DIC (10 mg/kg, IP) at 3 and $24 \mathrm{~h}$; (B) antiallodynic effect of CFX (200 mg/kg, IP) at 3 and $24 \mathrm{~h}$; (C) antiallodynic effect of CA (I0 mg/kg, IP) at 3 and $24 \mathrm{~h}$. Values are the mean \pm SEM of 8 rats per group. ${ }^{*} p<0.05$ vs Carr group ( 2 way ANOVA followed by a Dunnett post hoc test).

Abbreviations: ANOVA, analysis of variance; CA, clavulanic acid; Carr, carrageenan; CFX, ceftriaxone; DIC, diclofenac; IP, intraperitoneal; PWL, paw withdrawal latency; SEM, standard error of the mean.

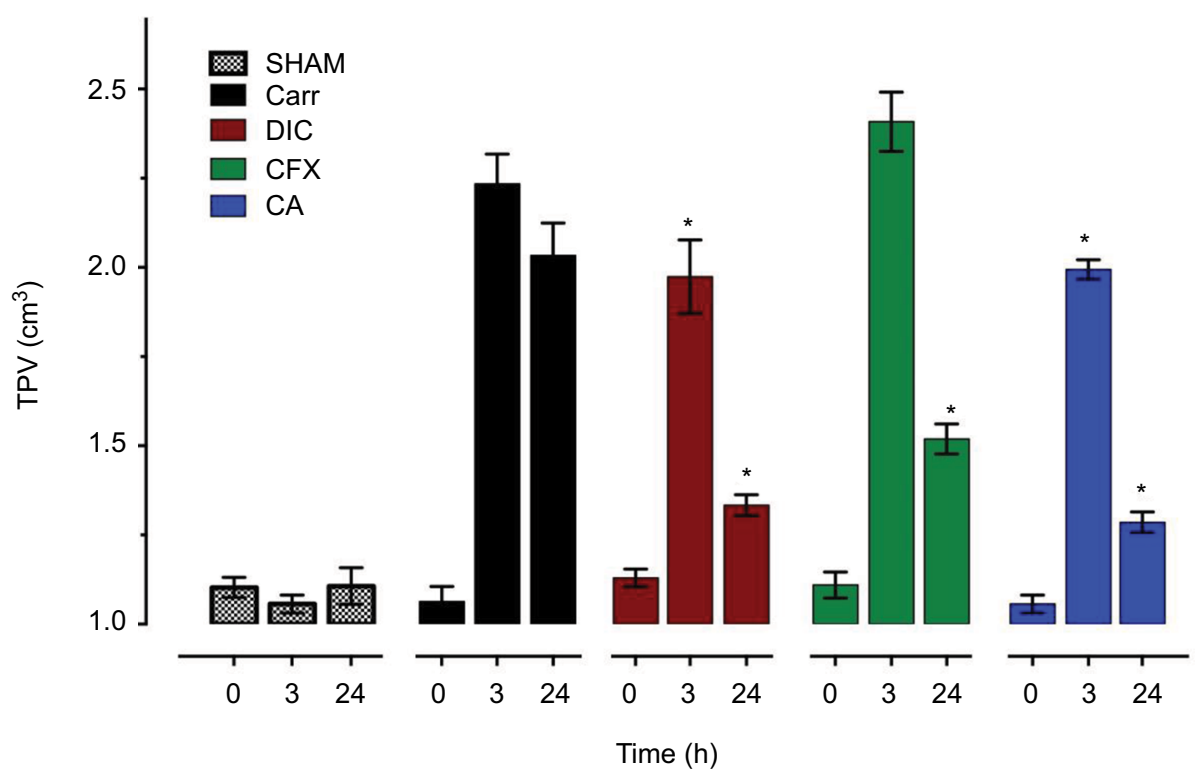

Figure 3 TPV and anti-inflammatory effects of drug administration: 0, 3, and $24 \mathrm{~h}$ after Carr administration.

Notes: Values are the mean \pm SEM of 8 rats per group. ${ }^{*} p<0.05$ vs Carr group at the corresponding time ( 2 way ANOVA followed by a Dunnett post hoc test).

Abbreviations: ANOVA, analysis of variance; CA, clavulanic acid; Carr, carrageenan; CFX, ceftriaxone; DIC, diclofenac; IP, intraperitoneal; SEM, standard error of the mean; TPV, total paw volume. 
did show a significant decrease at $24 \mathrm{~h}(1.5 \pm 0.04$ vs $2.0 \pm 0.09$ $\left.\mathrm{Carr}^{3} ; p<0.05\right)$. Furthermore, CA administration induced a significant decrease in TVP at both $3(1.9 \pm 0.02$ vs $2.2 \pm 0.08$ $\left.\mathrm{cm}^{3} ; p<0.05\right)$ and $24 \mathrm{~h}\left(1.2 \pm 0.02\right.$ vs $\left.2.0 \pm 0.09 \mathrm{~cm}^{3} ; p<0.05\right)$ in comparison with Carr at the corresponding time (Figure 3 ).

\section{Serum cytokine concentration}

To establish a possible systemic cytokine concentration modulation induced by either CFX of CA administration, serum proinflammatory (TNF- $\alpha$ ) or anti-inflammatory (IL-10) molecule concentrations were analyzed 3, 24, and $48 \mathrm{~h}$ after Carr and drugs administration. First, we established a single baseline SHAM group TNF- $\alpha(21.9 \pm 1.34 \mathrm{pg} / \mathrm{mL})$ and IL-10 (372.1 $\pm 69.69 \mathrm{pg} / \mathrm{mL})$ serum concentrations. Three hours after Carr administration, there was a significant increase in TNF- $\alpha(73.6 \pm 11.16$ vs $21.9 \pm 1.34 \mathrm{pg} / \mathrm{mL} ; p<0.05)$ but not in IL-10 (1,329.2 \pm 526.03 vs $372.1 \pm 69.69 \mathrm{pg} / \mathrm{mL} ; p>0.05)$ levels. Moreover, no significant difference was found at 24 and $48 \mathrm{~h}$ observations either for TNF- $\alpha(17.9 \pm 2.51$ and $16.7 \pm 2.29$ vs $21.9 \pm 1.34 \mathrm{pg} / \mathrm{mL}$, respectively; $p>0.05)$ or IL-10 (533.0 \pm 80.49 and $192.1 \pm 32.08$ vs $372.14 \pm 69.69 \mathrm{pg} / \mathrm{mL}$, respectively; $p>0.05$ ) levels compared with the SHAM (Figure 4).

DIC administration induced a significant decrease of TNF- $\alpha$ serum concentration $3 \mathrm{~h}$ after administration $(23.3 \pm 3.18$ vs $73.6 \pm 11.16 \mathrm{pg} / \mathrm{mL} ; p<0.05)$ however, no significant difference was found in any other observation point at $24(14.7 \pm 1.37 \mathrm{vs} 17.9 \pm 2.51 \mathrm{pg} / \mathrm{mL}, p>0.05)$ and 48 $\mathrm{h}(15.8 \pm 2.58$ vs $16.7 \pm 2.29 \mathrm{pg} / \mathrm{mL} ; p>0.05)$ in comparison with Carr at the corresponding time. On the other hand, we did not find any difference in IL-10 serum concentration at 3 $(1,464.1 \pm 404.93$ vs $1,329.2 \pm 526.03 \mathrm{pg} / \mathrm{mL} ; p>0.05)$ or $48 \mathrm{~h}$

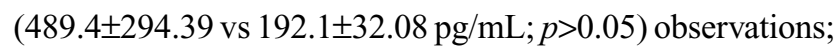
however, there was a significant increase in IL-10 serum concentration at the $24 \mathrm{~h}(3,919.6 \pm 903.20$ vs $533.0 \pm 80.49$ $\mathrm{pg} / \mathrm{mL} ; p<0.05)$ time point in comparison with Carr at the corresponding time point (Figure 4).

A ANF- $\alpha$

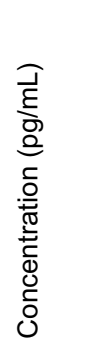
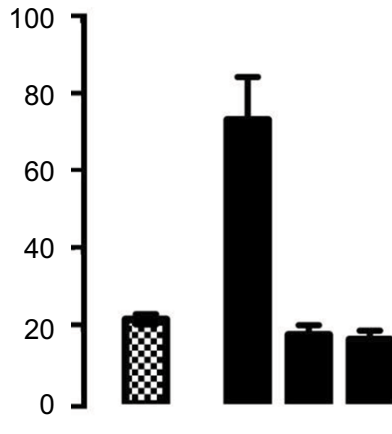

B

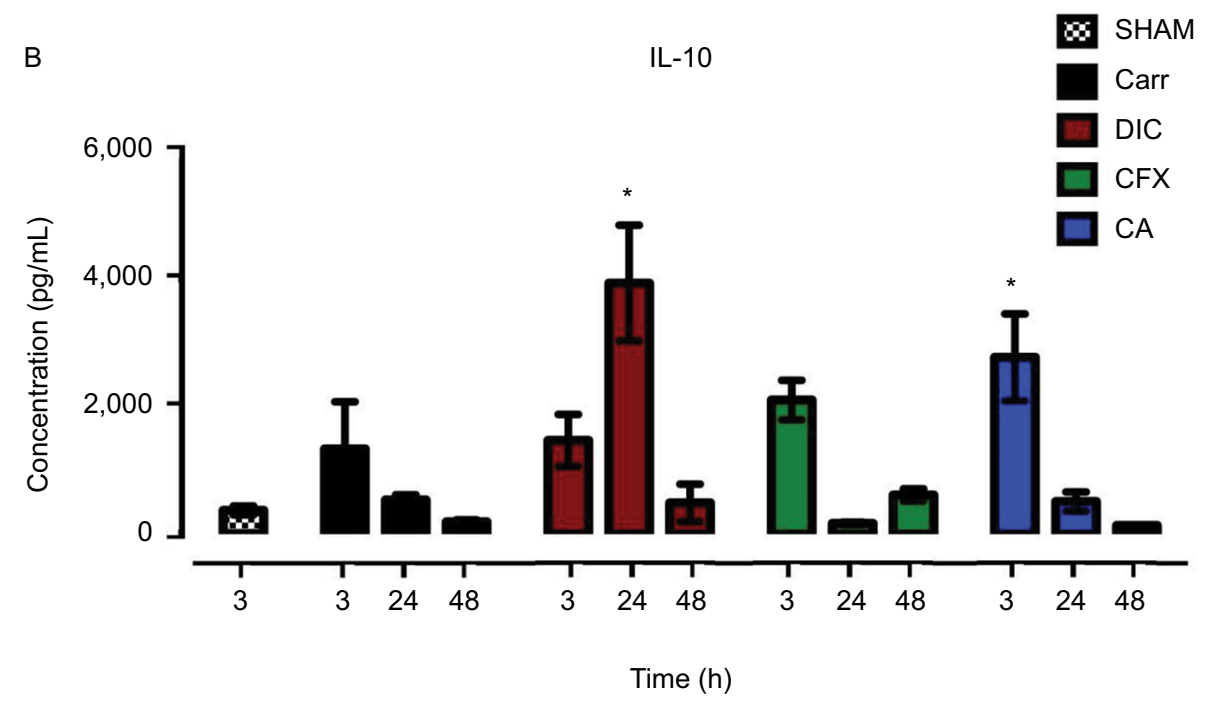

Figure 4 Cytokine serum concentration.

Notes: (A) TNF- $\alpha$ serum concentration at 3, 24, and $48 \mathrm{~h}$ after Carr intraplantar administration. (B) IL- 10 serum concentration at 3, 24 , and $48 \mathrm{~h}$ after Carr intraplantar administration. Values are the mean \pm SEM of 4 rats per group. * $p<0.05$ vs Carr group at the corresponding time ( 2 way ANOVA followed by a Dunnett post hoc test). Abbreviations: ANOVA, analysis of variance; CA, clavulanic acid; Carr, carrageenan; CFX, ceftriaxone; DIC, diclofenac; IP, intraperitoneal; SEM, standard error of the mean. 
Meanwhile, CFX administration did show a significant reduction in TNF- $\alpha$ at $3 \mathrm{~h}(33.7 \pm 3.48$ vs $73.6 \pm 11.16 \mathrm{pg} / \mathrm{mL}$; $p<0.05)$ observation, but no significant difference at either 24 $(9.9 \pm 0.23$ vs $17.9 \pm 2.51 \mathrm{pg} / \mathrm{mL} ; p>0.05)$ or $48 \mathrm{~h}(13.3 \pm 1.80$ vs $16.7 \pm 2.29 \mathrm{pg} / \mathrm{mL} ; p>0.05)$ in comparison with Carr at the corresponding time. Moreover, CFX administration did not induce a significant difference in serum IL-10 concentration at $3(2,094.7 \pm 307.38$ vs $1,329.2 \pm 526.03 \mathrm{pg} / \mathrm{mL} ; p>0.05)$, $24(167.7 \pm 20.57$ vs $533.0 \pm 80.49 \mathrm{pg} / \mathrm{mL} ; p>0.05)$, or $48 \mathrm{~h}$ $(612.0 \pm 95.74 \mathrm{vs} 192.1 \pm 32.08 \mathrm{pg} / \mathrm{mL} ; p>0.05)$ in comparison with Carr at the corresponding time (Figure 4).

On the other hand, CA administration induced a significant decrease of TNF- $\alpha$ concentration $3 \mathrm{~h}$ after administration $(38.1 \pm 5.98$ vs $73.6 \pm 11.16 \mathrm{pg} / \mathrm{mL} ; p<0.05)$ but not at 24 $(10.7 \pm 0.29$ vs $17.9 \pm 2.51 \mathrm{pg} / \mathrm{mL} ; p>0.05)$ or $48 \mathrm{~h}(14.5 \pm 1.82$ vs $16.7 \pm 2.29 \mathrm{pg} / \mathrm{mL} ; p>0.05)$ in comparison with Carr at the corresponding time. Furthermore, there was a significant increase in IL-10 concentration $3 \mathrm{~h}$ after administration $(2,758.7 \pm 678.19$ vs $1,329.2 \pm 526.03 \mathrm{pg} / \mathrm{mL} ; p<0.05)$ but not at $24(508.9 \pm 150.73$ vs $533.0 \pm 80.49 \mathrm{pg} / \mathrm{mL} ; p>0.05)$ or $48 \mathrm{~h}$ (137.7 \pm 5.25 vs $192.1 \pm 32.08 \mathrm{pg} / \mathrm{mL} ; p>0.05$ ) in comparison with Carr at the corresponding time (Figure 4).

\section{Discussion}

In this work, we present evidence of an acute mechanic and thermal antiallodynic effect of 2 BLMs on a Carr-induced inflammatory pain model. Also, we showed that this effect could be related to a possible direct modulation in serum TNF- $\alpha$ and IL-10 concentrations induced by both CA and CFX administration. Furthermore, we found an antiinflammatory effect of both BLMs $24 \mathrm{~h}$ after administration. To validate our experimental approach, we determined that Carr induced mechanical and thermal allodynia, as previously reported, ${ }^{16}$ and confirmed that DIC, a nonsteroidal analgesic clinically used in the inflammatory pain treatment, administration induced an acute antiallodynic effect. ${ }^{17}$

BLMs, which includes CFX and CA, currently represent one of the most commonly used therapeutic approaches in the infectious disease clinical field. ${ }^{18}$ However, Rothstein et $\mathrm{al}^{6}$ showed that after $48 \mathrm{~h}$ of BLM exposure in human and in rat astrocyte cultures, an increase in the expression of glutamate transporter GLT1 was observed. Although CA was not tested, these findings could be extended to this molecule since it shares the $\beta$-lactam moiety. ${ }^{19}$ After this discovery, several groups focused on CFX and found that it induced neuroprotection, ${ }^{20}$ inhibited drug seeking reinstatement, ${ }^{21}$ and showed antiepileptic properties. ${ }^{22}$ In the pain research area, CFX induces analgesia in both chronic neuropathic and acute inflammatory ${ }^{10}$ pain models. In the clinical setting, CFX has also been shown to induce analgesia in chronic inflammatory arthritis patients ${ }^{23}$ and in postoperative pain. ${ }^{5}$ On the other hand, CA has recently been proven to induce analgesia in a neuropathic pain model after continuous daily administration for at least 10 days. ${ }^{24}$ In most of these studies, however, results were pointed toward GLT1 upregulation and, therefore, glutamatergic neurotransmission modulation.

Our study showed that CFX did not induce an acute mechanical antiallodynic effect. However, it did induce an increase in PWL $3 \mathrm{~h}$ after administration in a plantar test model. This finding resembles our previous report as we also found that CFX administration induced thermal analgesia 6 min after intraperitoneal administration. ${ }^{8}$ We hypothesized that this effect could be related to a dopaminergic effect induced by CFX as it was blocked by haloperidol coadministration. Moreover, the acute antiallodynic effect of CFX was previously demonstrated by Stepanovic-Petrovic et al, ${ }^{10}$ in a model of acute inflammatory pain, although they reported a modest antiallodynic effect of CFX. The difference in the effect found in the first $3 \mathrm{~h}$ vs the one found 24 and $48 \mathrm{~h}$ after CFX administration may be explained by a poor penetration of CFX in an intact blood-brain barrier (BBB). ${ }^{25}$ Peripheral inflammation induced by Carr has previously been shown to alter spinal $\mathrm{BBB}^{26}$ and, hence, may increase the penetration of CFX into the spinal cord tissue after several hours of inflammation induction.

Additionally, we provide evidence of an acute antiallodynic effect of CA administration. CA is used as an adjuvant for other BLMs antibiotic effects as it has a negligible antibiotic effect by itself but it inhibits the $\beta$-lactamase molecules, the main resistance mechanism for BLMs. ${ }^{19}$ Similarly to CFX, CA induces GLT1 overexpression, ${ }^{7}$ and also has numerous effects in the central nervous system (CNS), for example it induces dopamine and serotonin release, ${ }^{27}$ is neuroprotective, ${ }^{28,29}$ has anxiolytic properties, ${ }^{30}$ and shows medullary dopaminergic modulation. ${ }^{31}$ Also, acute antiallodynic effect was previously reported in inflammatory pain models $^{32}$ where a significant effect of CA administration in the acute phase of the formalin test was reported. Moreover, in patients with low back pain, CA has shown analgesic properties. $^{33}$

Again, similar to CFX, CA-mediated effects in our model might be attributed to mechanisms different to GLT1 overexpression. This statement stems from the fact that Rothstein et $a l^{6}$ demonstrated GLT1 overexpression as early as $24 \mathrm{~h}$ after CA administration at similar doses than the one used by us, and we observed thermal antiallodynic effects in the first 
180 min after its administration. Also, as discussed above, these same doses of CA induce several other CNS effects.

The antiallodynic effect shown by CA may be related to its CNS concentration. This is suggested by the fact that it has a much greater permeability through the intact $\mathrm{BBB},{ }^{34}$ and its serum concentration-time curve displays a similar profile to our PWT and PWL time curve. ${ }^{34,35}$ Indeed, we observed a greater mechanical antiallodynic effect at $60 \mathrm{~min}$ at $10 \mathrm{mg} / \mathrm{kg}$, which coincides with the peak serum concentration after a dose of CA. ${ }^{35}$

Our findings also show that BLMs may have antiinflammatory properties as both CFX and CA groups showed a significant reduction in paw volume $24 \mathrm{~h}$ after Carr administration. Furthermore, CA also induced this effect $3 \mathrm{~h}$ after initial administration, which would mean that, although both molecules may have similar effects as GLT1 expression regulators, their immunological effect could be different. Moreover, this effect resembles the analgesic properties of CA (vide supra) and could be related also with a facilitated pass through the BBB or other tissues.

Our data suggest a mechanism of action different to gene expression induction to explain CFX and CA antiallodynic effect. We considered that it was probably related to a direct immune modulation since CA has previously been shown to have peripheral anti-inflammatory effects. ${ }^{12}$ Our results show that both CFX and CA decrease the Carr-mediated rise in serum TNF- $\alpha$ concentrations in a similar amount to DIC. TNF- $\alpha$, one of the main inflammatory cytokines, can alter nociceptor response by increasing tetrodotoxin-resistant $\mathrm{Na}+$ channels and decreasing $\mathrm{K}+$ conductance, enhancing pain transmission. ${ }^{36}$ In addition, peripheral TNF- $\alpha$ can be transported in a retrograde manner to the dorsal horn of the spinal cord, ${ }^{37}$ thus potentiating the glutamatergic signaling by downregulating the expression of GluR2 subunits of AMPA receptors, which render the AMPA receptor highly permeable to calcium. ${ }^{38}$ This could indicate that continuous administration of either CFX or CA in an inflammatory disease could protect a patient from developing chronic pain.

Furthermore, we found that CA induced a significant increase in the anti-inflammatory cytokine, IL-10, $3 \mathrm{~h}$ after administration. This finding opens a different perspective on CA analgesic effect as it may be related to a direct immunomodulatory effect and not only by dopaminergic modulation as we previously reported. ${ }^{7}$ Also, IL-10 increase may explain the acute anti-inflammatory effect shown by CA administration (vide supra), thus strengthening our prior conjecture. Moreover, the fact that CA induced a more potent effect than CFX with 100-fold lower dose and a lack of antibiotic effect makes it more suitable to be translated into clinical use.

\section{Conclusion}

In summary, to the best of our knowledge, we are the first group to provide evidence that both CFX and CA cause an analgesic effect on a Carr inflammatory pain model and that said analgesic effect differs between each BLM. In addition, our results provide evidence of an anti-inflammatory effect of both molecules $24 \mathrm{~h}$ after administration and a direct TNF- $\alpha$ and IL-10 serum concentration modulation.

\section{Acknowledgments}

This work was part of Ochoa-Aguilar A's doctoral thesis in Biomedical Sciences at the National Autonomous University of Mexico. Also, this work was partially supported by the UNAM-DGAPA-PAPIIT-IN204416 project.

\section{Disclosure}

The authors report no conflicts of interest in this work.

\section{References}

1. Kong KF, Schneper L, Mathee K. Beta-lactam antibiotics: from antibiosis to resistance and bacteriology. APMIS. 2010;118(1):1-36.

2. Saudagar PS, Survase SA, Singhal RS. Clavulanic acid: a review. Biotechnol Adv. 2008;26(4):335-351.

3. Hajhashemi V, Dehdashti K. Antinociceptive effect of clavulanic acid and its preventive activity against development of morphine tolerance and dependence in animal models. Res Pharm Sci. 2014;9(5): 315-321.

4. Hu Y, Li W, Lu L, et al. An anti-nociceptive role for ceftriaxone in chronic neuropathic pain in rats. Pain. 2010;148(2):284-301.

5. Macaluso A, Bernabucci M, Trabucco A, et al. Analgesic effect of a single preoperative dose of the antibiotic ceftriaxone in humans. J Pain. 2013;14(6):604-612.

6. Rothstein JD, Patel S, Regan MR, et al. $\beta$-Lactam antibiotics offer neuroprotection by increasing glutamate transporter expression. Nature. 2005;433(7021):73-77.

7. Kim J, John J, Langford D, Walker E, Ward S, Rawls SM. Clavulanic acid enhances glutamate transporter subtype I (GLT-1) expression and decreases reinforcing efficacy of cocaine in mice. Amino Acids. 2016;48(3):689-696.

8. Ochoa-Aguilar A, Sotomayor-Sobrino M, Jaimez R, Rodríguez R, Plancarte-Sánchez R, Ventura-Martinez R. Antiallodynic activity of ceftriaxone and clavulanic acid in acute administration is associated with serum TNF- $\alpha$ modulation and activation of dopaminergic and opioidergic systems. Drug Dev Res. 2017;78(2):105-115.

9. Pinho-Ribeiro FA, Verri WA Jr, Chiu IM. Nociceptor sensory neuronimmune interactions in pain and inflammation. Trends Immunol. 2017;38(1):5-19.

10. Stepanovic-Petrovic RM, Micov AM, Tomic MA, Kovacevic JM, Boskovic BD. Antihyperalgesic/antinociceptive effects of ceftriaxone and its synergistic interactions with different analgesics in inflammatory pain in rodents. Anesthesiology. 2014;120(3):737-750.

11. Ware MA, Bennett GJ. Case report: long-standing complex regional pain syndrome relieved by a cephalosporin antibiotic. Pain. 2014;155(7): 1412-1415.

12. Banani A, Maleki-Dizaji N, Garjani A, Soraya H, Mostafalou S, Ziaee M. Clavulanic acid exhibits anti-inflammatory effects on carrageenan-induced paw edema model of inflammation in rats. Ann Biol Res. 2012;3(7):3312-3320.

13. Zimmermann M. Ethical guidelines for investigations of experimental pain in conscious animals. Pain. 1983;16(2):109-110. 
14. NOM-062-ZOO-1999. Official Mexican Norm for animal care and management. Secretaría de salud. Especificaciones técnicas para la producción, cuidado y uso de los animales de laboratorio.

15. Bennett GJ, Xie YK. A peripheral mononeuropathy in rat that produces disorders of pain sensation like those seen in man. Pain. 1988;33(1):87-107.

16. López-Avila A, Rodríguez-Manzo G, Coffeen U, del Ángel R, Pellicer F. Self-injury behaviour induced by intraplantar carrageenan infiltration: a model of tonic nociception. Brain Res Protoc. 2004;13(1):37-44.

17. Ku EC, Wsvary JM, Cash WD. Diclofenac sodium (GP 45840, Voltaren), a potent inhibitor of prostaglandin synthetase. Biochem Pharmacol. 1975;24(5):641-643.

18. Paul M, Lador A, Grozinsky-Glasberg S, Leibovici L. Beta lactam antibiotic monotherapy versus beta lactam-aminoglycoside antibiotic combination therapy for sepsis. Cochrane Database Syst Rev. 2014;(1):CD003344.

19. Reading C, Cole M. Clavulanic acid: a beta-lactamase-inhibiting betalactam from Streptomyces clavuligerus. Antimicrob Agents Chemother. 1977;11(5):852-857.

20. Mimura K, Tomimatsu T, Minato K, et al. Ceftriaxone preconditioning confers neuroprotection in neonatal rats through glutamate transporter 1 upregulation. Reprod Sci. 2011;18(12):1193-1201.

21. Sari Y, Smith KD, Ali PK, Rebec GV. Upregulation of GLT1 attenuates cue-induced reinstatement of cocaine-seeking behavior in rats. J Neurosci. 2009;29(29):9239-9243.

22. Jelenkovic AV, Jovanovic MD, Stanimirovic DD, Bokonjic DD, Ocic GG, Boskovic BS. Beneficial effects of ceftriaxone against pentylenetetrazole-evoked convulsions. Exp Biol Med (Maywood). 2008;233(11): 1389-1394.

23. Caperton EM, Heim-Duthoy KL, Matzke GR, Peterson PK, Johnson RC. Ceftriaxone therapy of chronic inflammatory arthritis. A double-blind placebo controlled trial. Arch Intern Med. 1990;150(8):1677-1682.

24. Kristensen P, Gegelashvili G, Munro G, Heegaard A, Bjerrum O. The $\beta$-lactam clavulanic acid mediates glutamate transport-sensitive pain relief in a rat model of neuropathic pain. Eur J Pain. 2018;22(2): 282-294.

25. Nau R, Sorgel F, Eiffert H. Penetration of drugs through the bloodcerebrospinal fluid/blood-brain barrier for treatment of central nervous system infections. Clin Microbiol Rev. 2010;23(4):858-883.

26. Huber JD, Hau VS, Borg L, Campos CR, Egleton RD, Davis TP. Blood-brain barrier tight junctions are altered during a 72-h exposure to $\lambda$-carrageenan-induced inflammatory pain. Am J Physiol Heart Circ Physiol. 2002;283(4):H1531-H1537.
27. Kost GC, Selvaraj S, Lee YB, Kim DJ, Ahn CH, Singh BB. Clavulanic acid increases dopamine release in neuronal cells through a mechanism involving enhanced vesicle trafficking. Neurosci Lett. 2011;504(2):170-175.

28. Huh Y, Ju MS, Park H, et al. Clavulanic acid protects neurons in pharmacological models of neurodegenerative diseases. Drug Dev Res. 2010;71(6):351-357.

29. Kost GC, Selvaraj S, Lee YB, Kim DJ, Ahn CH, Singh BB. Clavulanic acid inhibits MPP(+)-induced ROS generation and subsequent loss of dopaminergic cells. Brain Res. 2012;1469:129-135.

30. Kim DJ, King JA, Zuccarelli L, et al. Clavulanic acid: a competitive inhibitor of beta-lactamases with novel anxiolytic-like activity and minimal side effects. Pharmacol Biochem Behav. 2009;93(2):112-120.

31. Chan JS, Kim DJ, Ahn CH, Oosting RS, Olivier B. Clavulanic acid stimulates sexual behaviour in male rats. Eur J Pharmacol. 2009;609(1-3): 69-73.

32. Hajhashemi V, Dehdashti K. Antinociceptive effect of clavulanic acid and its preventive activity against development of morphine tolerance and dependence in animal models. Res Pharm Sci. 2014;9(5):315-321.

33. Albert HB, Sorensen JS, Christensen BS, Manniche C. Antibiotic treatment in patients with chronic low back pain and vertebral bone edema (Modic type 1 changes): a double-blind randomized clinical controlled trial of efficacy. Eur Spine J. 2013;22(4):697-707.

34. Munch R, Luthy R, Blaser J, Siegenthaler W. Human pharmacokinetics and CSF penetration of clavulanic acid. J Antimicrob Chemother. 1981;8(1):29-37.

35. Adam D, de Visser I, Koeppe P. Pharmacokinetics of amoxicillin and clavulanic acid administered alone and in combination. Antimicrob Agents Chemother. 1982;22(3):353-357.

36. Gudes S, Barkai O, Caspi Y, Katz B, Lev S, Binshtok AM. The role of slow and persistent TTX-resistant sodium currents in acute tumor necrosis factor- $\alpha$-mediated increase in nociceptors excitability. $J \mathrm{Neu}$ rophysiol. 2015;113(2):601-619.

37. Lin YT, Ro LS, Wang HL, Chen JC. Up-regulation of dorsal root ganglia BDNF and trkB receptor in inflammatory pain: an in vivo and in vitro study. J Neuroinflammation. 2011;8:126.

38. Kopach O, Kao SC, Petralia RS, Belan P, Tao YX, Voitenko N. Inflammation alters trafficking of extrasynaptic AMPA receptors in tonically firing lamina II neurons of the rat spinal dorsal horn. Pain. 2011;152(4): 912-923.

39. Hargreaves K, Dubner R, Brown F, et al. A new and sensitive method for measuring thermal nociception in cutaneous hyperalgesia. Pain. 1988;32:77-88.
Journal of Pain Research

\section{Publish your work in this journal}

The Journal of Pain Research is an international, peer reviewed, open access, online journal that welcomes laboratory and clinical findings in the fields of pain research and the prevention and management of pain. Original research, reviews, symposium reports, hypothesis formation and commentaries are all considered for publication.
Dovepress

The manuscript management system is completely online and includes a very quick and fair peer-review system, which is all easy to use. Visit http://www.dovepress.com/testimonials.php to read real quotes from published authors. 